Revista Tecné, Episteme y Didaxis: TED. Año 2014, Número Extraordinario. ISSN Impreso: 0121-3814, ISSN web: 2323-0126

Memorias, Sexto Congreso Internacional sobre Formación de Profesores de Ciencias. 08 al 10 de octubre de 2014, Bogotá

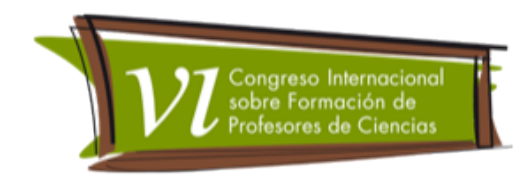

\title{
El Pck en profesores de Biología: Aportes y limitaciones
}

Fonseca A Guillermo '

Categoría 2. Trabajo de investigación

\section{Resumen}

La presente ponencia se constituye en un avance del proyecto de investigación: El Conocimiento Didáctico del Contenido de profesores de biología en formación inicial sobre el concepto de biodiversidad: Un estudio de caso en la práctica pedagógica en la Universidad Distrital Francisco José de Caldas, señalando algunos de los resultados acerca de la propia configuración del PCK publicados en la base de datos ERIC. La interpretación se realiza sobre siete artículos acerca del PCK en profesores de biología, en donde es posible evidenciar dos perspectivas en su conceptualización, el PCK como producto de la transformación ó de la integración entre el conocimiento de la materia y el conocimiento pedagógico. Respecto a las componentes del PCK se establecen dos posibilidades el reconocimiento del modelo de Magnusson y otros (1999) ó el de Park y Oliver, (2008a). Además se advierte acerca del abandono de la comprensión epistémica del PCK en las investigaciones objeto de lectura y el papel del profesor en la construcción de su propio conocimiento profesional.

\section{Palabras clave}

PCK, profesores de biología, conocimiento profesional.

\section{Objetivo}

Aportar en la compresión del PCK a través de la lectura critica de los resultados de investigaciones publicados en la base de datos ERIC.

\section{Marco teórico}

El PCK es la categoría que con mayor probabilidad, permite distinguir entre la comprensión del contenido del especialista y la comprensión del pedagogo Shulman (1986), Abell (2008), plantea que el PCK se está acercando al estatus de

\footnotetext{
1 Universidad Distrital Francisco José de Caldas- guifon20@yahoo.com
} 
Revista Tecné, Episteme y Didaxis: TED. Año 2014, Número Extraordinario. ISSN Impreso: 0121-3814, ISSN web: 2323-0126

Memorias, Sexto Congreso Internacional sobre Formación de Profesores de Ciencias. 08 al 10 de octubre de 2014, Bogotá

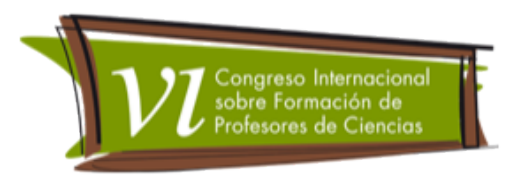

paradigma, que es compartido por toda la comunidad de investigación y que guía nuestro pensamiento sobre el aprendizaje del maestro.

Kind (2009) señala que el PCK aporta en la formación de los futuros profesores y que contribuye a los maestros con experiencia en el desarrollo de una práctica pedagógica reflexionada. Si los alumnos pueden ser incitados para comprender el PCK como el conocimiento que ellos mismos están aprendiendo, esto puede contribuir positivamente al desarrollo de los futuros profesores de ciencias, ya que serian más conscientes del proceso que están llevando.

Respecto a lo anterior Kind (2009), propone que los modelos de transformación del PCK parecen ser los más útiles para la educación del profesor de ciencias. Loughran, Mulhall y Berry $(2004,2006)$ reconocen la integración del conocimiento disciplinar y el conocimiento experiencial pedagógico y profesional, además plantean que la enseñanza requiere mucho más que ofrecer conocimiento de los contenidos a los estudiantes, y que el aprendizaje del estudiante es considerablemente más que absorber la información precisa para su devolución. Park y Oliver (2008a) señalan la necesidad de continuar trabajando sobre este conocimiento en razón de que la naturaleza amorfa de PCK causa dificultad en su uso explícito como una herramienta conceptual en otras palabras, ha sido difícil construir una imagen clara, no sólo de cómo se desarrolla el andamiaje PCK en los docentes, sino también de cómo evaluarlo una vez construido.

\section{Metodología}

Los artículos objeto de revisión desde los aspectos anteriormente señalados, corresponden a los publicados en la base de datos ERIC (palabras claves PCK Biología), teniendo como criterio de selección, que el contenido se refiere al tratamiento de conceptos propios de la enseñanza de la biología, sobre estos artículos se realizo un ejercicio interpretativo desde los principios de análisis de contenido desde la conceptualización del PCK.

Tabla 1. Investigaciones reportadas acerca del PCK en biología base de datos ERIC

\begin{tabular}{|c|c|c|c|}
\hline Autor & Año & Titulo & Universidad \\
\hline $\begin{array}{l}\text { Melanie } \\
\text { Juttner, } \\
\text { Williame } \\
\text { Boone, Soony } \\
\text { Park, Birgit J, }\end{array}$ & & $\begin{array}{l}\text { Development and use of a test } \\
\text { instrument to measure biology } \\
\text { teachers' content knowledge (CK) } \\
\text { and pedagogical content } \\
\text { knoledge (PCK) }\end{array}$ & $\begin{array}{l}\text { Biology Education, Faculty of Biology, } \\
\text { Ludwig-Maximilians-University of Munich, } \\
\text { Winzererstr. } 45 / \text { II, } 80797 \quad \text { Munich, } \\
\text { Germany. Miami University, Oxford, OH, } \\
\text { USA. University of lowa, lowa City, IA, USA }\end{array}$ \\
\hline
\end{tabular}


Revista Tecné, Episteme y Didaxis: TED. Año 2014, Número Extraordinario. ISSN Impreso: 0121-3814, ISSN web: 2323-0126

Memorias, Sexto Congreso Internacional sobre Formación de Profesores de Ciencias. 08 al 10 de octubre de 2014, Bogotá

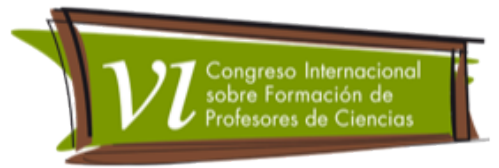

\begin{tabular}{|c|c|c|c|}
\hline & & & \\
\hline $\begin{array}{l}\text { Stephan } \\
\text { Schmelzing, } \\
\text { Jan H Van } \\
\text { Driel, Melanie } \\
\text { Juttner, } \\
\text { Stefanie } \\
\text { Brabdenbusch, } \\
\text { Angela } \\
\text { Sandmann, y } \\
\text { Birgit Neuhaus. }\end{array}$ & 013 & $\begin{array}{l}\text { Development, Evaluation, and } \\
\text { Validation of a paper- and pencil } \\
\text { test form measuring two } \\
\text { components of biology teachers' } \\
\text { pedagogical content knowledge } \\
\text { concernig the "Cradiovascular } \\
\text { system" }\end{array}$ & $\begin{array}{l}\text { Research Group and Graduate School } \\
\text { "Teaching and Learning Science" } \\
\text { University of Duisburg-Essen Essen, } \\
\text { Germany. } \\
\text { ICLON-Leiden University Graduate } \\
\text { School of Teaching Leiden, Netherlands. } \\
\text { Biology Education, Faculty of Biology } \\
\text { Ludwig-Maximilians-University Munich. }\end{array}$ \\
\hline $\begin{array}{l}\text { Brown P., } \\
\text { Friedrichesen } \\
\text { P., Abell S. }\end{array}$ & 2012 & $\begin{array}{l}\text { The Development of prospective } \\
\text { secondary biology teachers PCK, } \\
\text { EEUU }\end{array}$ & $\begin{array}{l}\text { DuBray Middle School, Fort Zumwalt } \\
\text { School District, St. Charles, MO, USA. } \\
\text { Science Education Center, University of } \\
\text { Missouri, Columbia, MO, USA }\end{array}$ \\
\hline $\begin{array}{l}\text { Park Soonhye y } \\
\text { Chen Ying - } \\
\text { Chin }\end{array}$ & 2012 & $\begin{array}{l}\text { Mapping out the integratio of the } \\
\text { components of pedagogical } \\
\text { content knolewlwde (PCK): } \\
\text { Examples from high sChool Biology } \\
\text { Classrooms }\end{array}$ & sity of Iowa, Iowa City, IA, USA \\
\hline $\begin{array}{l}\text { Soonhye } \text { Park, } \\
\text { Jeong - Yoon } \\
\text { Jang, Ying- } \\
\text { Chin Chen, } \\
\text { Jinhong Jung }\end{array}$ & 2011 & $\begin{array}{l}\text { Is pedagogical content knowledge } \\
\text { (PCK) necessary for reformed } \\
\text { science teaching?: Evidence from } \\
\text { an empirical study }\end{array}$ & $\begin{array}{l}\text { Department of Teaching \& Learning, } \\
\text { University of lowa, Department of } \\
\text { Kinesiology \& Physical Education, } \\
\text { Northern Illinois University }\end{array}$ \\
\hline $\begin{array}{l}\text { Kapyla, } \\
\text { Markku, } \\
\text { Heikkinen, } \\
\text { Jussi-Pekka y } \\
\text { Asunta Tuula }\end{array}$ & 2009 & $\begin{array}{l}\text { Influence of Content Knowledge } \\
\text { on Pedagogical Content } \\
\text { Knoledge: Tehe case of teaching } \\
\text { photosynthesis and plant growth }\end{array}$ & $\begin{array}{l}\text { Department of Teacher Education, PL 35, } \\
\text { Jyväskylä University, } 400014 \text { Finland }\end{array}$ \\
\hline $\begin{array}{l}\text { Rachel Cohen } \\
\text { y Ana Yarden }\end{array}$ & 2009 & $\begin{array}{l}\text { Experienced Junior - High - School } \\
\text { Teachers' PCK in Light of a } \\
\text { Curriculum Change: "The Cell is to } \\
\text { be Studied LongitudinallY" }\end{array}$ & $\begin{array}{l}\text { Department of Science Teaching, } \\
\text { Weizmann Institute of Science, Rehovot } \\
\text { 76100, Israel }\end{array}$ \\
\hline
\end{tabular}

\section{Resultados}

Los resultados se observan en la tabla 1, en donde se presentan los artículos objeto de lectura y sobre los cuales se presentan posteriormente algunas conclusiones. 
Revista Tecné, Episteme y Didaxis: TED. Año 2014, Número Extraordinario. ISSN Impreso: 0121-3814, ISSN web: 2323-0126

Memorias, Sexto Congreso Internacional sobre Formación de Profesores de Ciencias. 08 al 10 de octubre de 2014, Bogotá

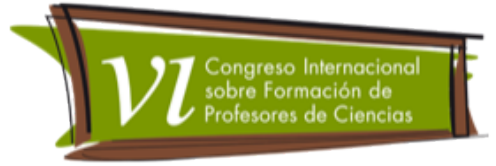

\section{Conclusiones}

Si bien el PCK, se constituye en un referente importante en relación con la formación de profesores, respecto a la consideración de reconocer en el PCK, un conocimiento profesional propio de la profesión docente, en el planteamiento de Shulman no se observa un desarrollo acerca de la naturaleza epistémica de este conocimiento, asunto en el cual se puede avanzar en el marco de la epistemología de la práctica, que se menciona de manera tangencial en el propio planteamiento del autor cuando plantea algunos elementos de la sabiduría de la práctica, sin embrago este aspecto no es objeto de discusión en los proyectos de investigación objeto de lectura. Este asunto convoca a resignificar el propio PCK, en razón que no operaria en una racionalidad de orden técnico, (de la teoría a la práctica) sino que se ubicaría en una epistemología de la práctica en donde el constructivismo seria el nicho de actuación.

El papel del maestro en el programa de Shulman, (los artículos revisados) se sitúa más como un profesional que aplica unos modelos de desarrollo curricular y las investigaciones se conducen a establecer las distancias o cercanías entre los presupuestos de estos modelos y la actuación en el aula, asunto que aleja al maestro como un profesional intelectual que a través de procesos de investigación de su propia práctica produce conocimiento y desde allí contribuye a la consolidación de una comunidad académica a la cual pertenece. Así, en este programa, aparece el paradigma perdido del conocimiento enseñable, pero desaparece el maestro como constructor de conocimiento.

El PCK, tiene como referente la "transformación del contenido" para hacerlo compresible a los estudiantes, es decir el referente es el conocimiento científico, para explicar los fenómenos naturales, aspecto que reduce el papel de la escuela en la comprensión de los fenómenos, se desconoce otras vías por ejemplo la idea de complejización del conocimiento de los estudiantes apoyados en otras fuentes de conocimientos, que circulan en la escuela. Tal perspectiva de Shulman, ubica a la enseñanza y el aprendizaje en un lugar neutral, aspecto que desde el ámbito educativo es una reducción de la condición política del acto educativo.

La separación entre los investigadores en educación y los profesores de las escuelas, en razón que en los trabajos revisados, el maestro se reconoce como un sujeto sobre el cual se hace un ejercicio de investigación, pero el mismo no se involucra como agente activo en el proceso. 
Revista Tecné, Episteme y Didaxis: TED. Año 2014, Número Extraordinario. ISSN Impreso: 0121-3814, ISSN web: 2323-0126

Memorias, Sexto Congreso Internacional sobre Formación de Profesores de Ciencias. 08 al 10 de octubre de 2014, Bogotá

En los trabajos objeto de lectura se evidencia una fragmentación de las componentes del PCK, aspecto sobre el cual se han realizado diversas observaciones en la necesidad de comprender que estas componentes son dinámicas en su propia naturaleza producto de las interacciones que se establecen en el acto de enseñar.

En relación con la propia configuración del PCK sobre los temas de biología objeto de las investigaciones no se presenta de manera explícita el conocimiento que se produce desde el propio saber derivado de la experiencia de los profesores de biología.

\section{Referencias bibliográficas}

Abell, S. (2008) Twenty Years Later. Does Pedagogical Content Knowledge remain a useful. International Journal of Science Education, 30 (10), 1405-1416.

Cohen, R. \& Yarden, A. (2009). Experienced Junior-High-School Teachers' PCK in Light of a Curriculum Change: "The Cell is to be Studied Longitudinally". Research in Science Education, 39, 131-155.

Juttner, M., Boone, M., Park, S., \& Neuhaus, B. (2013) Development and use of a test instrument to measure biology teachers' content knowledge (CK) and pedagogical content knoledge (PCK). Educational assessment, evaluation and accountability, 25, 45-67.

Kapyla, M., Heikkinen, J., \& Asunta, T. (2009). Influence of Content Knowledge on Pedagogical Content Knoledge: The case of teaching photosynthesis and plant growth. International Journal of Science Education, 31 (10), 1395-1415.

Kind, V. (2009). Conocimiento pedagógico del contenido en la educación científica: Perspectivas y posibilidades de progreso. Estudios en ciencias de la Educación, 45 (2), 169-204.

Loughran, J., Mulhall, P. \& Berry, A. (2004). In Search of Pedagogical Content Knowledge in Science: Developing Ways of Articulating and Documenting Professional Practice. Journal of Research in Science Teaching, 41 (4), 370391. 
Revista Tecné, Episteme y Didaxis: TED. Año 2014, Número Extraordinario. ISSN Impreso: 0121-3814, ISSN web: 2323-0126

Memorias, Sexto Congreso Internacional sobre Formación de Profesores de Ciencias. 08 al 10 de octubre de 2014, Bogotá

Loughran, J., Berry, A., \& Mulhall, P. (2006). Understanding and developing science teachers' pedagogical content knowledge. Rotterdam: Sense Publishers

Magnusson, S., Krajcik, J., \& Borko, H. (1999). Nature, sources and development of pedagogical content knowledge. En J. Gess-Newsome \& N. G. Lederman (Eds.), Examining pedagogical content knowledge (págs. 95-132). Dordrecht: Kluwer Academic Publishers.

Park, S., \& Chen, Y. (2012). Mapping out the integration of the components of pedagogical content knowledge (PCK): Examples from high School Biology Classrooms. Journal of research in science teaching, 1-20.

Park, S., Jang, J., Chen, Y., \& Jung, J. (2011). Is pedagogical content knowledge (PCK) necessary for reformed science teaching?: Evidence from an empirical study. Research in Science Education, 41, 245-260.

Park, S., \& Oliver, S. (2008a). Revisiting the conceptualisation of pedagogical content knowledge (PCK): PCK as a conceptual tool to understand teachers as professionals. Research in Science Education, 38(3), 261-284.

Schmelzing, S., Van Driel, J., Juttner, M., Brabdenbusch, S., Sandmann, A., \& Neuhaus, B. (2013). Development, Evaluation, and Validation of a paperand pencil test form measuring two components of biology teachers' pedagogical content knowledge concernig the "Cardiovascular System". International Journal of Science and Mathematics Education.

Shulman, L. S. (1986). Those who understand: Knowledge growth in teaching. Educational Researcher, 15 (2), 4-14. 